\title{
OBJECT-BASED TEACHING AND LEARNING FOR A CRITICAL ASSESSMENT OF DIGITAL TECHNOLOGIES IN ARTS AND CULTURAL HERITAGE
}

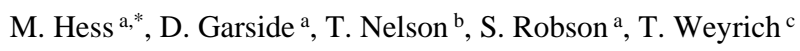 \\ a Department of Civil, Environmental and Geomatic Engineering, University College London, UK - (m.hess, daniel.garside.14, \\ s.robson)@ucl.ac.uk \\ ${ }^{\mathrm{b}}$ UCL Culture, University College London, UK - tonya.nelson@ucl.ac.uk \\ ${ }^{c}$ Department of Computer Science, University College London, UK - t.weyrich@cs.ucl.ac.uk
}

Special Session: Teaching and Learning

KEY WORDS: learning, object-based teaching, 3D recording, photogrammetry, laser scanning, digital technologies, cultural heritage, interdisciplinarity

\begin{abstract}
:
As cultural sector practice becomes increasingly dependent on digital technologies for the production, display, and dissemination of art and material heritage, it is important that those working in the sector understand the basic scientific principles underpinning these technologies and the social, political and economic implications of exploiting them. The understanding of issues in cultural heritage preservation and digital heritage begins in the education of the future stakeholders and the innovative integration of technologies into the curriculum. This paper gives an example of digital technology skills embedded into a module in the interdisciplinary UCL Bachelor of Arts and Sciences, named "Technologies in Arts and Cultural Heritage", at University College London.
\end{abstract}

\section{INTRODUCTION}

This paper is introducing the opportunities of teaching digital technology skills for use in the cultural sector and beyond.

The interdisciplinary elective course 'Technologies in Arts and Cultural Heritage' in the Bachelor of Arts and Sciences at University College London combines classroom-based theory and practical application of photography, 3D recording technologies and critical reflection on technologies used and digital heritage (Weyrich, Nelson and Robson, 2017). The syllabus is a combination of approaches from different disciplines: computer science, geomatic engineering, and museum studies. The module aims at acquisition of crossdisciplinary knowledge as well as of practical transferable skills. The objective of the module is to examine the role technology plays in the development, distribution, and preservation of art and material heritage.

\section{OBJECT-BASED TEACHING AND LEARNING IN EDUCATION}

Object-based teaching and learning as methodology in conjunction with the use of university collections can benefit teaching across disciplines and departments (Hannan, Chatterjee and Duhs, 2013). It has been observed that the use of OBL as 'student-centred' and 'activity-based learning' will be beneficial to students as a strong way of internalising and retaining theoretical and applied knowledge, (Marie, 2011) and
(Chatterjee, 2011). Furthermore, the use of new technologies and objects contributes to active and experiential learning experiences (Kolb, 1984) and will help learners to understand issues involved in digital and physical reproduction of an object.

This case study is a reflection on the practice of object-based learning (OBL), in this case museum objects, in connection with digital technologies and museum objects in the module BASc2082 in the past four years (Weyrich, Nelson and Robson, 2017).

Object-based learning in connection with new digital technologies has been discussed by (Loy, 2014). Another approach proposes eMaking and 3D printing in the classroom for design education to enhance creative output by students in a new learning environment. Tiballi describes the use of the OBL through re-creating objects in $2 \mathrm{D}, 3 \mathrm{D}$ and digitally, in order to increase the observational skills, contextual knowledge, and empathetic imagination of the students. In particular, 'haptic engagement, which includes tactile, kinaesthetic, experiential and embodied knowledge, requires a student to become fully immersed in the learning environment' (Tiballi, 2015, p. 61). Hidalgo even proposes of the possible re-shaping of universities by 3D printing (Hidalgo, 2012). Teaching specialists at UCL found that $\mathrm{OBL}$ promotes the acquisition and dissemination of subject-specific and cross-disciplinary knowledge, observational, practical and other transferable skills' (Chatterjee, Hannan and Thomson, 2015).
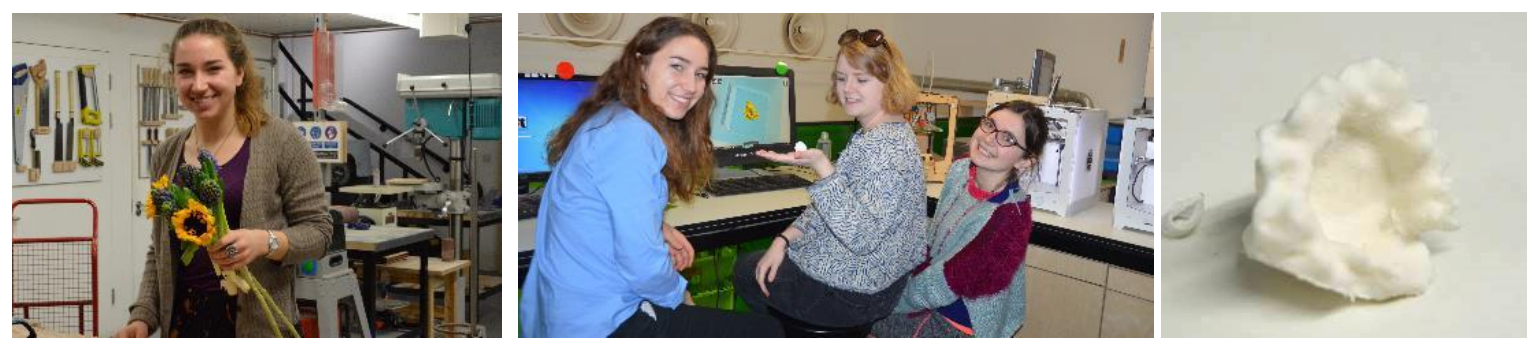

Figure 1. Students during 3D imaging (left) and 3D printing (middle and right) at the Institute of Making in 2015. The project addressed objects in zoological collections and the need to create models for teaching of ephemeral specimens, here sunflowers. 
For education in heritage studies, museum and studies, conservation and heritage conservation, the methodology of OBL seems obvious. Digital Heritage technologies used for teaching and learning foster engagement of students with the 'object', in this case the real world museum objects or spaces.

\section{CASE STUDY "TECHNOLOGIES IN ARTS AND CULTURAL HERITAGE”}

\subsection{Course contents}

The module offers a historical view of the relationship between technology and art / cultural heritage and challenges students to use this knowledge to investigate the implications of using new technologies in contemporary cultural practice. For example, students examine how the invention of the camera spawned both a new form of artistic expression and reproduction method that put concepts of authenticity, originality and authorship into question. Students are asked to consider how this learning relates to cultural practice in the digital world. The course focuses on technological developments in four areas: reproduction techniques, colour and light theory, materials/appearance and illustration/abstraction, and draw on a range of scientific, philosophical and political texts. UCL Museums and Collections are seen as case studies and as learning spaces to understand the implications of existing and new technologies on heritage practice and the consumption of art and material culture. Seminars will mix lectures with visits to UCL's museums and other UCL facilities, such as the Digitisation Suite of the UCL Centre for Digital Humanities, where practical applications of technologies can be explored.

\subsection{Learning digital technologies skills in a group project}

The main coursework, of this module translates Object-based learning (OBL) into a group project with the aim to select an object, and answer a 'real life curatorial question in a museum' using digital reproduction technology (e.g. physical reproduction through 3D printing for object handling for the visually impaired museum question). The final student presentation reflects a critical assessment of the methodologies used and the decisions taken. The hands-on element and a trial and error process play a great role. The mark represents $50 \%$ of the total mark of the module.

\subsection{Learning environment}

In the years 2014 and 2015, students conducted their group project in a new learning environment at the UCL Institute of Making. The Institute of Making is "a multidisciplinary research club for those interested in the made world: from makers of molecules to makers of buildings, synthetic skin to spacecraft, soup to diamonds, socks to cities. Membership of and day-to-day access to the Institute is available to all UCL staff and students",
(UCL Institute of Making, 2017). After a Health and Safety induction, students enjoy pre-hours access and use 3D scanning and 3D printing equipment. Once familiar with the space, groups easily spread out across the room with moveable desks and chairs to work on their projects. Students were eagerly using traditional tools or digital equipment, Figure 2. When, in 2016, the space was no longer available, a significant change in student behaviour was observed when the course took place in a seminar room. Students arrived to a pre-arranged desks and chairs and initially needed encouragement to use equipment and re-arrange the room to their needs. Nevertheless, he final projects were as exciting as previous years, because students learned to bring along all equipment they needed to be able to complete actions like the physical destruction of a replica, Figure 3.

\subsection{Object choices}

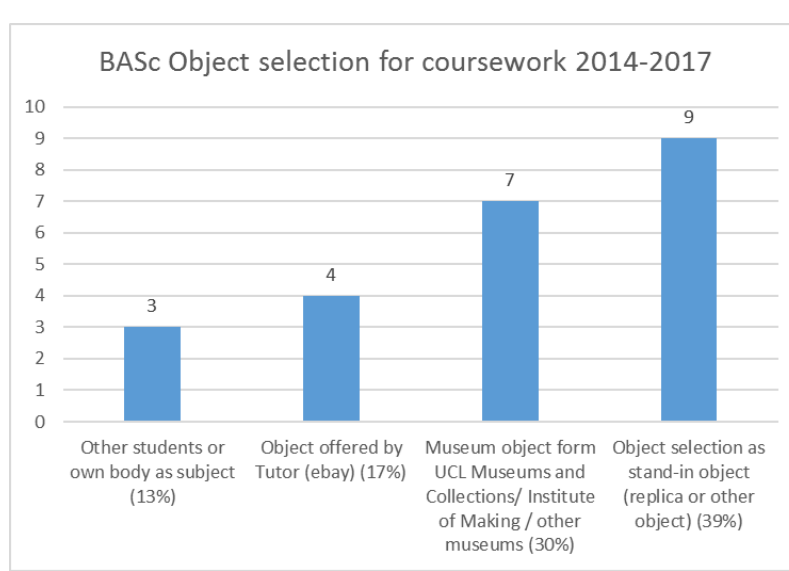

Figure 3. Object selection for 3D coursework in BASc2082.

When analysing the object selection of students over the past three years, most projects were using 'stand-in' objects selected by the students themselves to illustrate their project idea (39\%). A third of the successful projects used UCL Museum objects $(30 \%)$. This is remarkable - taking into account the logistical challenge of arranging access with the museum curator and the effort to bring 3D imaging kit into the museum space.

3.5 Practical application of 3D imaging towards a critical understanding of digital technologies used in Digital Heritage

The assignment for small groups of students relate to an object of their choice, with the task to define their own topic sourced from preceding lectures and discussion to answer a 'real life curatorial question in a museum'. Participants are asked to develop a project plan, conduct 3D imaging, and then creatively modify $3 \mathrm{D}$ print the object to produce a physical output. Failures are accepted and encouraged as valuable experiences on the learning path to gain practical skills and knowledge. The use of different $3 \mathrm{D}$ recording technologies allows students to understand the advantages or disadvantages first hand.
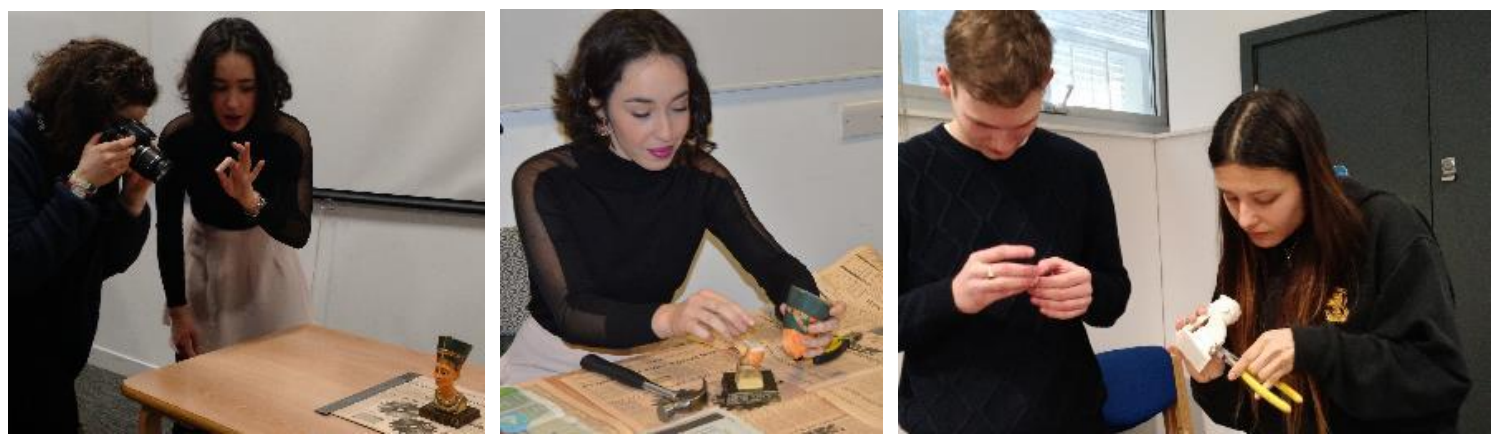

Figure 2. Student in classroom: Photographing the object towards a photogrammetric reconstruction (left), intentionally destroying a replica object Nefertiti (centre), cleaning a 3D print of a portrait bust of the student on the left (right), in 2016. 
Firstly, students familiarised themselves with the basics of image creation, photography theory and practice, and post-processing (Adobe Photoshop). Subsequently, the following technologies are available for use: photogrammetry with DSLR-Cameras using Autodesk products (at the time of writing ReMake, formerly 123DCatch or Memento) or Smartphone Apps (Trnio), 3D laser scanning using a Nextengine laser line triangulation scanner, 'low cost 3D' using an Asus Xtion sensor with Skanect or ReconstructMe software. For post-processing, the 3D records Autodesk Meshmixer or Meshlab are used. Notably, Autodesk products are freely available for students. Students with access to other software also successfully employed Rhinoceros or other CAD packages. Students then have the opportunity, and the timemanagement challenge, to $3 \mathrm{D}$ print their $3 \mathrm{D}$ models on a Makerbot Mini or on Ultimaker 3D printers.

At the end of the course, a multimedia presentation of physical and digital products is evaluated by expert guest critiques. Students deliver a critical assessment of the methodologies used and decisions taken. They are conversant in the newly acquired technical vocabulary and are able to answer questions about advantages and disadvantages about the digital heritage technologies the used for their projects. Students will recognize that issues in the preservation and treatment of heritage are transferable to larger scales of collections or other types of objects. Wider issues related to our worlds' cultural heritage, for example heritage at risk and its digital recording and virtual reconstruction are now on the radar of the students completing the 'Technologies in Arts and Cultural Heritage' module. Further, reflections about material culture, authenticity, reproduction, and copyright in the art market are discussion topics during class and the final presentations.

Evaluation criteria for the final presentation delivered with a projected presentation were: 1) organisation and logical progression of presentation content, 2) demonstration of effort to critically analyse 3D technology and its uses, 3) mastery of technical elements of 3D technology as demonstrated through clear and accurate explanation of methodologies and processes used, 4) effective use/ display of object (3D printed/ real) and 2D / 3D image to explain or demonstrate presentation points, 5) engaging and lively presentation style and creativity.

Students are also asked to prepare a brief illustrated report about their project. Its assessment is based on the following criteria: 1) use of a variety of methods for 3D imaging, 2) understanding and engagement, 3 ) critical reflection on challenges and the quality of the report, 4) production of a physical output/ 3D print (time management), 5) ingenuity of the project.

\subsection{Reflections on current issues in the use of digital technologies in cultural heritage}

After theory, discussions about current topics are encouraged. An example is the clandestine 3D scanning of Nefertiti at Neues Museum Berlin by (Nelles and Al-Badri, 2016), another example is the reproduction of the Arch of the destroyed temple of Baal in Syria, (Richardson, 09:33) and (Factum Arte, 2017). In the latter, students reflect about the notion of buildings and objects 'restored in their old glory' and about the messages sent by destroyed and virtually restored art. Also, students were enthusiastic that they could get involved in crowdsourced or citizen science movements such as Project Mosul/ Rekrei (Vincent and Coughenour, 2016), or Micropasts (Bonacchi et al., 2014) to contribute to the digital reconstruction and documentation of Heritage at risk.

\subsection{Conclusions on the Module development and outcomes for learners}

Object-Based Learning (OBL) centred around objects, be it a real museum object or a stand-in object, has proven to be of great efficacy to instigate learning and successful acquisition of subject-specific knowledge and transferable skills by learning technological skills in the domain of digital workflows for heritage conservation. In the last years, the learning curve to acquire skills connected with the creation of $3 \mathrm{D}$ digital images and outputs has flattened significantly since the advent of internet forums, tutorials and easily accessible software and consumer cameras, which make it possible for students to quickly immerse themselves into their digital technologies project for cultural heritage and art. The resulting effects of teaching on the students are often only visible after some time passed: in this case in the number of students who go on to pursue internships, a career, or research in the field of digital heritage technologies.

\subsection{Teaching transferable skills beyond the classroom door}

Academic education is aiming at career development, learning and employability according to the UK Higher Education Academy (Watts and Team, 2006). This section is exploring the results of teaching transferable skills in an undergraduate module by observing students' activities after or during their studies with relation to the case study module content.

At UCL, the Connected Curriculum (CC), is a benchmark for connecting research-based teaching and education at UCL, and its main aims are shown in Figure 4, (UCL Arena and UCL Teaching and Learning, 2016) and (Fung and UCL CALT, 2014). The discussed module 'Technology in Arts and Cultural Heritage' is able to cover several aspects of the CC, and more specifically 'Students connect academic learning with workplace learning' (Dimensions 3) and 'Students make connections across subjects and out to the world' (Dimension 4).

From the point of the teacher, transferable skills acquired in the module include knowledge transfer about colour science, human perception, and perspective; and practical skills include the use of image processing software, 3D modelling software, use of photography and 3D imaging techniques for the recording of real-world objects to create a $3 \mathrm{D}$ digital image, and for 3D printing. Soft skills such as 'teamwork, project management, creativity, enterprise and leadership' (CC Dimension 4) as well as interpersonal communication, teamwork, and critical thinking skills helped to complete the practical coursework. This module is also part of the mission of interdisciplinarity for the Bachelor of Arts and Sciences (UCL BASc, 2016).

To collect evidence of students' follow-on activities, a short survey was sent to all 55 students who had taken the course between 2014-2016 (Hess, 2016). Nine responses were obtained, probably due to students' time restriction during exam period. Additionally, information about students' activities from the years 2014/2015 were collated with the help of the course director, course administrator and internships officer, and internet research. Information for Year 2016 is reflected through 7 answers to the anonymous survey. An overview of the outcome is given in Figure 5.

From the point of view of students, transferable skills (citations from survey):

- 3D scanning, modification, and printing.

- Interested in exploring more about photogrammetry regarding its machine vision aspect

- Both the technical skills of 3D technology and the application of it - how 3D technology can be contextualised to express 
certain information or achieve certain things. e.g. I used the different effects in [software to modify a 3D model] (and then $3 D$ print them) to represent different forms of movement in a physical model of the ad films.

- First experience with how to use technologies in the arts, it opened many new possibilities to me, especially if I want to continue in the field of arts.

Seven students completed internships or worked in technology and/or museums. Examples are an internship at the Hornimann Museum London, internship at the Orleans House Gallery, Wilhelm Hack Museum in Berlin. Related activities include work in digital communications at the Times Education Supplement. One student remarked that she unexpectedly used her 3D printing skills in a publishing company. One student continued with a final year dissertation in direct relation to the course (collecting $3 \mathrm{D}$ printed material).

In summary, the number of students who have already continued, or are intending to continue using the skills from BASc2082 shows a rising trend. Roughly, $20 \%$ of students continue to use their transferable skills from module BASc2082 in academic learning or in work practice and daily life. Closer analysis of students' destinations will become clearer in the next years. Continued knowledge transfer of skills towards professional career development of the student, or towards further academic enquiries, are also embedded within UCL's aims institutional Education strategy (UCL, 2016).

\section{LEARNING OPPORTUNITIES IN DIGITAL HERITAGE TECHNOLOGIES}

\subsection{Digital Heritage in Higher Education}

A map of Heritage educational opportunities in the UK and in Germany shows offers of study in Heritage, Museology and Digital Heritage educational offers; the map is work in progress and has no claim to completeness (Hess, 2017). Currently most studies related to heritage are located within university faculties of arts, humanities, archaeology, architecture/ built environment and design. The engineering and geomatics departments (not shown on the map) offer remote sensing and reality capture courses. In autumn 2017, this offer will be complemented with a dedicated MSc course on Digital Heritage Technologies in Germany (Otto-Friedrich Universitaet Bamberg, 2016) and an MRes in Science and Engineering in Arts, Heritage and Archaeology at UCL Institute for Sustainable Heritage (UCL ISH, 2017).

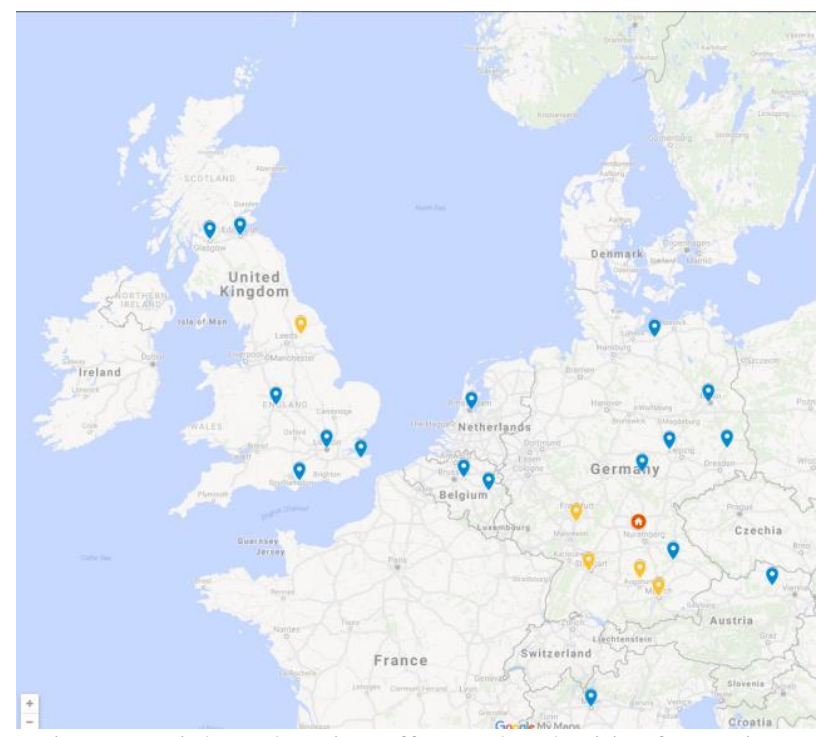

Figure 6. Higher education offers and authorities for Heritage Studies (no claim on completeness)

\subsection{Digital Technology skill in the cultural sector through} Continuous Professional Development (CPD)

As the cultural sector is recognizing the opportunities of digital technologies (Nelson and MacDonald, 2012), courses are offered to build in-house capacity for museums and collections to offer on online 3D experience of the collections or pathways towards Virtual Reality experiences and 3D printing, as it democratises access to museum holdings and offers new ways of engaging with newer audiences.

A brief case study should show the availability of courses in London in the past 12 months (no claim to completeness):

- The UK Association for Historical and Fine Arts Photography (AHFAP) is holding a yearly conference. When in 2014, after an inspiring talk by T. Weyrich (Weyrich et al., 2014), the question was raised if they thought the learning of 3D imaging would be essential to their daily work, to an the audience of professional photographers and archivists by, about 50\% raised their hand. In a conference 2 years later, more than $50 \%$ documentation professionals were actively engaging with 3D imaging and were interested to hear about this (Hess and Hindmarch, 2016).

- The Digital Preservation Coalition workshop 2016, named 3D4ever: building three-dimensional models to last. This workshop even hosted two different photogrammetry workshops. The treatment of 3D data and long-term

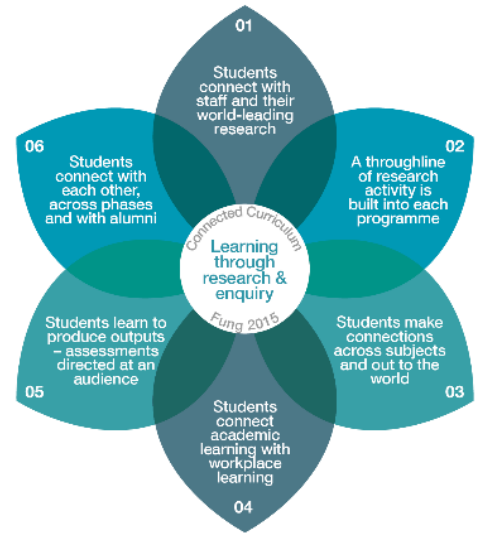

Figure 4. UCL Dimensions of the Connected Curriculum for research-based education

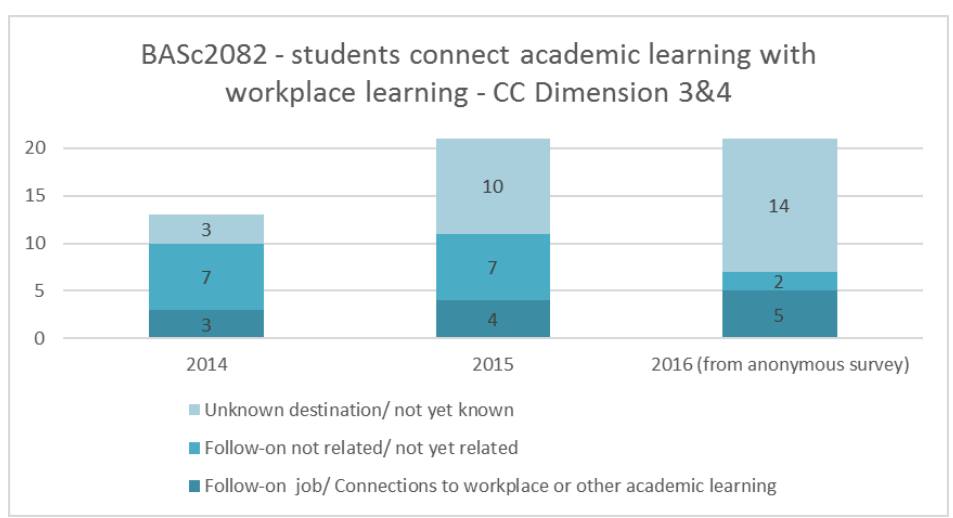

Figure 5. Development of follow-on activities of BASc2082 students in academic or workplace learning. 
preservation of this type of data was critical topic (Wellcome Collection and Digital Preservation Coalition, 2016).

- The Museum of London hosted multiple workshops to reach out to museum professionals to get a first introduction to 3D imaging.

- The UK Museum Association and MuseumTech increasingly introduces workshops for professionals to familiarise themselves with the new opportunities of 3D recording for collections and objects.

- Ongoing Horizon2020 projects researching heritage documentation, dissemination and infrastructure will also offering many workshops and conference contributions. The British Museum will have a workshop through the IPERION project hosted by the British Museum in November 2017.

\subsection{Conferences and Workshops}

A great number of conferences deal with the technical questions of digitisation. To name a few: UCL SEAHA, VAST, CIPA ICOMOS , Digital Heritage, ISPRS, 3DArch, Optical Metrology in SPIE Videometrics, EVA. All these conferences produce scientific proceedings, advantageous in the context of teaching and learning. The CIPA summer school is also a prominent example of excellent teaching of academics and researchers towards a scientific application of digital heritage technologies (CIPA ICOMOS, 2017)

\subsection{Self-taught learning in Digital Heritage}

Access to software to produce 3D images from photography is becoming more and more accessible. Smartphone Apps and cloud-computing website applications and software enable everyone to produce their own 3D model without expert knowledge. This is a quickly developing market and doubtlessly new sensors, software, and apps will develop in the next years, accessible and at affordable prices.

Increasingly, so-called 'Scanathons' are offered at museums, often facilitated through museum education groups, for example during the Digital Design Weekend at the Victoria and Albert Museum in London by 'Scan the World'(MyMiniFactory, 2017).

\section{CONCLUSIONS}

Object-based teaching and learning (OBL) for a critical assessment of digital technologies in arts and cultural heriage has proven effective.

The importance of digital workflows for heritage conservation should be examined at a scientific level but also towards usability of the stakeholders. Digital workflows are also important on an education on different levels: school and higher education, organised courses for continued professional development for museum and heritage professionals or for self-study. All learners will be able to give valuable feedback on the usability and new ideas on how to improve workflows for the use of digital technologies.

Teaching in digital heritage technologies should offer the opportunity on critical assessment and comparisons to known levels of quality, with parameters of metric, colorimetric or other specified scientific criteria, beyond the manufacturer specifications with known mechanisms of verification.

During learning, the option for experimentation and failure should be part of the experience to learn routine use of digital heritage technologies. At the same time users and learners need to be prepared to be flexible and open to adopt in future for technological innovation on the web and with different tools, new methods and newly developed sensors.

Outputs from digital technologies should have compliance with the local and country-specific codes of conduct in heritage and conservation, as well as with the archival and documentation levels for the authorities for the future of research and education of the next generation of heritage professionals.

\section{ACKNOWLEDGEMENTS}

Many thanks go out to the wonderful Bachelor of Arts and Sciences team of UCL's Faculty of the Arts and Humanities, especially to Carl Gombrich, Amanda Cater and Cristy Meadows, who made this module possible and provided their invaluable support throughout the years. Additional support, through provision of space and equipment loans, was kindly provided by the UCL Institute of Making, UCL Institute for Sustainable Heritage, UCL Centre for Digital Humanities and the 3DIMPact research group at UCL's Department of Civil, Environmental and Geomatic Engineering. Parts of the module reuse materials one of us co-developed with Szymon Rusinkiewicz for a Freshman Seminar at Princeton University, USA.

\section{REFERENCES}

Bonacchi, C. et al. (2014) 'MicroPasts - A community platform for conducting, designing and funding research into our human past'. Available at: http://micropasts.org/about/ (Accessed: 8 October 2014).

Chatterjee, H. J. (2011) 'Object-based learning in higher education: The pedagogical power of museums', Proceedings, 3 . Available at: http://edoc.hu-berlin.de/umacj/2010/chatterjee179/XML/Chatterjee_xdiml.xml (Accessed: 15 April 2014).

Chatterjee, H. J., Hannan, L. and Thomson, L. (2015) 'An Introduction to Object-Based Learning and Multisensory Engagement', in Engaging the Senses: Object-Based Learning in Higher Education. Ashgate, pp. 1-18. Available at: $/$ default.aspx ?page $=637 \&$ calcTitle $=1 \&$ isbn $=9781472446152$ (Accessed: 8 January 2016).

CIPA ICOMOS (2017) 'The International Committee for Documentation of Cultural Heritage (CIPA) - CIPA's website', April. Available at: http://cipa.icomos.org/ (Accessed: 19 April 2017).

Factum Arte (2017) IDA Palmyra Arch copy, Factum Foundation. Available at: http://www.factumfoundation.org/pag/236/ (Accessed: 23 February 2017).

Fung, D. and UCL CALT (2014) 'Connected Curriculum: Transforming Education at UCL', in.

Hannan, L., Chatterjee, H. J. and Duhs, R. (2013) 'Object Based Learning: A Powerful Pedagogy for Higher Education', in Boddington, A., Boys, J., and Speight, C. (eds) Museums and Higher Education Working Together. Farnham: Ashgate, pp. $159-168$

Hess, M. (2016) Opinio Survey: Follow-on activites after $B A S c 2082$, for students years 2014-2016. Available at: https://opinio.ucl.ac.uk/s?s=44035 (Accessed: 2 June 2016). 
Hess, M. (2017) Education in Digital Heritage Technologies, a Map. Available at https://www.google.com/maps/d/viewer?mid=1eHClPp-3rD7HrdrdgXJTaUKMzg (Accessed: 15 June 2017).

Hess, M. and Hindmarch, J. (2016) 'Wel(l)come@3D and 3DBOX. a modular kit for photogrammetry. (abstract)', in. Association for Historical and Fine Art Photography Conference 2016, London, UK: AHFAP. Available at: http://www.ahfap.org.uk/conferences/2016-conference/2016abstracts/ (Accessed: 15 June 2017).

Weyrich, T., Nelson, T. and Robson, S. (2017) Interdisciplinary electcive: BASC2082 Technology in Arts and Cultural Heritage, Bachelor of Arts and Sciences. Available at: http://www.ucl.ac.uk/basc/current/core/ie/basc2082 (Accessed: 31 January 2017).

Hidalgo, J. (2012) The future of higher education: reshaping universities through $3 D$ printing, Engadget. Available at: http://www.engadget.com/2012/10/19/reshaping-universitiesthrough-3d-printing/ (Accessed: 25 May 2016).

Kolb, D. A. (1984) 'Chapter 2: The Process of Experiential Learning', in Experiential Learning: Experience as the Source of Learning and Development. 1 edition. Englewood Cliffs, N.J: Prentice Hall. Available at: http://learningfromexperience.com/research_library/theprocess-of-experiential-learning/ (Accessed: 22 May 2014).

Loy, J. (2014) 'eLearning and eMaking: 3D Printing Blurring the Digital and the Physical', Education Sciences, 4(1), pp. 108-121. doi: 10.3390/educsci4010108.

Marie, J. (2011) 'The role of object-based learning in transferable skills development', Proceedings, 3. Available at: http://edoc.huberlin.de/umacj/2010/marie-187/XML/Marie_xdiml.xml (Accessed: 15 April 2014).

MyMiniFactory (2017) Scan The World. Available at: https://www.myminifactory.com/scantheworld/\#about (Accessed: 15 June 2017).

Nelles, J. N. and Al-Badri, N. (2016) Nefertiti Hack. The Other Nefertiti - artists release the 3D data of Nefertitis Head. Available at: http://nefertitihack.alloversky.com/ (Accessed: 31 January 2017).

Nelson, T. and MacDonald, S. (2012) 'A space for innovation and experimentation: University Museums as test beds for new digital technologies', in Jandl, S. S. and Gold, M. S. (eds) Academic Museums Takes Shape. MuseumsEtc. Available at: http://www.museumsetc.com/blogs/news/5296302-academicmuseums-takes-shape.

Otto-Friedrich Universitaet Bamberg (2016) Neuer Masterstudiengang „Digitale Denkmaltechnologien“, Pressemitteilungen der Universität Bamberg. Available at: http://www.uni-bamberg.de/presse/pm/artikel/neuer-

masterstudiengang-digitale-denkmaltechnologien/ (Accessed: 10 April 2017).

Richardson, N. (09:33) The Arch of Triumph of Palmyra is recreated in London - 1,800 years after it was built, The Telegraph. http://www.telegraph.co.uk/news/2016/04/08/why-the-arch-oftriumph-of-palmyra-is-being-recreated-in-london/ (Accessed: 23 February 2017).

Tiballi, A. (2015) 'Engaging the Past: Haptics and Object-Based Learning in multiple Dimensions', in Chatterjee, H. J. and Hannan, L. (eds) Engaging the Senses: Object-Based Learning in Higher Education. Ashgate, pp. 57-75. Available at: $/$ default.aspx ?page $=637 \&$ calcTitle $=1 \&$ isbn $=9781472446152$ (Accessed: 8 January 2016).

$\begin{array}{llll}\text { UCL (2016) UCL Education Strategy } & \text { 2016-21. Principal Theme } \\ 2 & \text { of } & \text { UCL2034. } & \text { Available }\end{array}$ https://www.ucl.ac.uk/srs/academic-manual/policy-az/learningand-teaching/strategy (Accessed: 2 June 2016).

UCL Arena and UCL Teaching and Learning (2016) Connected Curriculum: A distinctive approach to research-based education. Available at: http://www.ucl.ac.uk/teaching-learning/connectedcurriculum (Accessed: 11 May 2016).

UCL BASc (2016) More about interdisciplinarity (FAQ). Available https://www.ucl.ac.uk/basc/prospective/faq/interdisciplinarity (Accessed: 23 May 2016).

UCL Institute of Making (2017) UCL Institute of Making, Institute of Making. Available at: http://www.instituteofmaking.org.uk/ (Accessed: 15 June 2017).

UCL ISH (2017) Science and Engineering in Arts, Heritage and Archaeology MRes | UCL London's Global University. Available at: https://www.ucl.ac.uk/prospectivestudents/graduate/taught/degrees/science-engineering-artsheritage-archaeology-mres (Accessed: 15 June 2017).

Vincent, M. and Coughenour, C. (2016) Rekrei / Project Mosul, Rekrei / Project Mosul. Available at: http://projectmosul.org/ (Accessed: 10 May 2016).

Watts, A. G. and Team, E. S. E. C. (2006) Career development learning and employability. Higher Education Academy Heslington. Available at: https://www.heacademy.ac.uk/sites/default/files/id592_career_d evelopment_learning_and_employability.pdf (Accessed: 2 June 2016).

Wellcome Collection and Digital Preservation Coalition (2016) 3D4ever: building three dimensional models to last. Available at: https://wellcomecollection.org/3d4ever (Accessed: 15 June 2017).

Weyrich, T. et al. (2014) Heritage Imaging at UCL, Annual Conference of Association for Historical and Fine Art Photography (AHFAP). Available at: http://discovery.ucl.ac.uk/1455093/ (Accessed: 15 June 2017). 